\title{
Analysis of Skin Parameters of Korean Men According to the Parts of the Body for Integumentary Physiotherapy Research
}

\author{
So-Jung Kim¹, Ju-Hyun Kim², Jeong-Uk Lee3 ${ }^{3}$ Mee-Young Kim¹, Lim-Kyu Lee',4, Byoung-Sun Park1, \\ Seung-Min Yang1, Won-Deok Lee ${ }^{1}$, Ji-Woong Noh', Yong-Sub Shin'1, Doo-Ho Kim¹, Il-Hyun Kim¹, \\ Junghwan Kim ${ }^{5 *}$
}

${ }^{1}$ Laboratory of Health Science \& Nanophysiotherapy, Department of Physical Therapy, Graduate School, Yongin University, Yongin, South Korea

${ }^{2}$ Department of Physical Therapy, College of Health Welfare, Wonkwang Health Science University, Iksan, South Korea

${ }^{3}$ Department of Physical Therapy, College of Health Science, Honam University, Gwangju, South Korea

${ }^{4}$ The Team of Safety and Quality Management, Yeongwol Combined Cycle Power Plant Division, Korea Southern Power Plant, Busan, South Korea

${ }^{5}$ Department of Physical Therapy, College of Public Health \& Welfare, Yongin University, Yongin, South Korea

Email: ^junghwankim3@yongin.ac.kr

How to cite this paper: Kim, S.-J., Kim, J.-H., Lee, J.-U., Kim, M.-Y., Lee, L.-K., Park, B.-S., Yang, S.-M., Lee, W.-D., Noh, J.-W., Shin, Y.-S., Kim, D.-H., Kim, I.-H. and Kim, J. (2018) Analysis of Skin Parameters of Korean Men According to the Parts of the Body for Integumentary Physiotherapy Research. Health, 10, 467-486. https://doi.org/10.4236/health.2018.104038

Received: January 23, 2018

Accepted: April 25, 2018

Published: April 28, 2018

Copyright ( 92018 by authors and Scientific Research Publishing Inc. This work is licensed under the Creative Commons Attribution International License (CC BY 4.0).

http://creativecommons.org/licenses/by/4.0/

(c) (i) Open Access

\begin{abstract}
Studies have demonstrated that some cutaneous biophysical properties vary with the part of the body. The results to date of skin conditions in human skin of multiple parts of the body have not yet been well established. In this study, we assessed the differences in the skin's sebum, moisture, pores, wrinkles, pigmentation, and elasticity of each body part in Korean men in their 20s. A total of 34 healthy men were enrolled. A Skin Diagnosis Meter was used to measure the skin's surface sebum, moisture, pores, wrinkles, pigmentation, and elasticity of each body part. The sebum content was significantly higher on the face than at other sites. Moisture was significantly high on the feet. Pores were significantly high on the face. Wrinkles were significantly high on the face. Pigmentation was high on the face and neck, but not significantly. Elasticity was significantly high on the hands. In the correlation analysis results, sebum and pore were positively correlated, but sebum and moisture and wrinkle and elasticity were negatively correlated. For nearly the first time, this study resulted in systematic reference values for standardized biophysical measuring methods and body parts reflecting the skin physiology of healthy South Korean men. The results show that skin's surface sebum, moisture, pores, wrinkles, pigmentation, and elasticity vary with the part of the body.
\end{abstract}

\section{Keywords}

Sebum, Moisture, Pores, Wrinkles, Pigmentation, Elasticity, Total Body 


\section{Introduction}

The skin is important to protect the body from various internal and external factors caused by chemical and biochemical stress [1]. The typical structural layers of skin are well known: the hypodermis, dermis, and epidermis [2]. Sebum glands, sweat glands, and collagen and elastic fibers are located in the dermis; skin pores and melanocyte are located in the epidermis. The changes in the body due to aging are influenced by many factors. Skin changes can be caused by external factors, such as air pollution, smoke, and photoaging, in addition to chronological aging, resulting in increased skin pigmentation and wrinkles, defective epidermal permeability barrier function, and reduced skin elasticity [3] [4]. Moreover, the skin disorders of atopic dermatitis, psoriasis, and ichthyosis result from decreased stratum corneum hydration and altered permeability barrier function [5] [6] [7] [8]. Furthermore, impaired skin barrier function is typically found in dry skin, which exhibits the increased values of transepidermal water loss and skin surface $\mathrm{pH}$. This epidermal barrier insufficiency is reflected by a decrease in stratum corneum hydration and decreased amounts of natural moisturizing factor. Skin is influenced by internal factors, such as hormonal factors, which influence the secretory activity of human sebaceous glands [9]. The maximum sebum production of men occurs in their 20s, making them susceptible to skin diseases such as facial acne and dermatitis [10]. Studies show that large quantities of sebum and large pore can produce greasy skin and also cause adult diseases [11]. Recently, many male activities occur outside, such as physical activity, exposing them to sunlight [12] [13]. The ultraviolet (UV) radiation in sunlight has many positive influences on the human body, such as helping to release serotonin and playing an essential role in vitamin D synthesis [14] [15]. Among the different types of UV, ultraviolet B (UVA-B) sustains damage to the skin [16] [17]. So at this age, it is important for men to care for their skin [18]. And, normal physiological functions are still occurring in each part of the body, which can keep the skin healthy. In general, men have changed their skin care and grooming habits, and there is an increasing demand for cosmetic products for men [18]. The cosmetic product has a great effect on the skin [19]. Clinically, studies have shown that aloe, which is commonly used as a cosmetic product, affects collagen and fibroblast [20]. To date, however, very few studies have analyzed the skin function of adults in their $20 \mathrm{~s}$. Therefore, the objectives of this research were to analyze the skin in terms of the sebum content, moisture, pores, wrinkles, pigmentation, and elasticity in healthy South Korean men.

\section{Methods}

\subsection{Participants}

A total of 34 healthy male subjects aged 20 - 29 years were enrolled in this study. All subjects had no skin disorders at the study sites (Table 1). Seven sites were identified. No skin care products had been applied to the measured sites for at 
Table 1. General characteristics of participants.

\begin{tabular}{|c|c|c|}
\hline Variable & Classification & \\
\hline Age (yrs) & & $23.9 \pm 0.4$ \\
\hline Height $(\mathrm{cm})$ & & $175.1 \pm 0.6$ \\
\hline Weight $(\mathrm{kg})$ & & $70.7 \pm 2.2$ \\
\hline BMI $\left(\mathrm{kg} / \mathrm{m}^{2}\right)$ & & $23.0 \pm 0.6$ \\
\hline \multirow[t]{2}{*}{ Gender (\%) } & Male & $34(100.0)$ \\
\hline & Female & - \\
\hline \multirow[t]{4}{*}{ Blood type (\%) } & $\mathrm{AB}$ & $4(11.8)$ \\
\hline & A & $12(35.3)$ \\
\hline & B & $12(35.3)$ \\
\hline & $\mathrm{O}$ & $6(17.6)$ \\
\hline \multirow[t]{2}{*}{ Smoking (\%) } & Smoker & $8(23.5)$ \\
\hline & Nonsmoker & $26(76.5)$ \\
\hline \multirow[t]{4}{*}{ Drinking (\%) } & Yes & $34(100.0)$ \\
\hline & No & - \\
\hline & 1 bottle/week & $21(61.8)$ \\
\hline & 2 bottle/week & $13(38.2)$ \\
\hline PSQI (score) & & $2.2 \pm 0.1$ \\
\hline \multirow[t]{3}{*}{ Skin injury (\%) } & Injuries experience & $15(44.1)$ \\
\hline & Injuries inexperience & $17(50.0)$ \\
\hline & Don't know & $2(5.9)$ \\
\hline \multirow[t]{4}{*}{ Type of skin injury (\%) } & Abrasion & $8(23.5)$ \\
\hline & Burns & $5(14.7)$ \\
\hline & Incised wound & $2(5.9)$ \\
\hline & Nothing & $19(55.9)$ \\
\hline
\end{tabular}

All data were presented as the mean \pm SE. SMM, skeletal muscle mass; BFM, body fat mass; WHR, waist-hip ratio; BMI, body mass index; PSQI, Pittsburgh sleep quality index; RH and LH, right and left hand; RF and LF, right and left foot; Dom-H, dominant hand; Dom-F, dominant foot.

least $24 \mathrm{~h}$ prior to the measurement, and the measured sites had not been washed with soaps or surfactants for at least $2 \mathrm{~h}$ prior to measurement. No one had gone without sleep the night before measuring, and cosmetics, sport activities, and saunas were not allowed for at least $12 \mathrm{~h}$ before the measurements. Participants were asked to complete a questionnaire via individual in-depth interviews, which took 30 minutes per person [21].

\subsection{Measurements}

All measurements were performed in a sitting room. Human body was divided into eight segment: face (anterior), ear (anterior and posterior), neck (anterior and posterior), body (anterior and posterior), upper limb (anterior and posterior), hand (dorsal and palm), lower limb (anterior and posterior), foot (dorsal and sole) (Figure S1). Face segment was divided into five points: anterior face 
P1 (most anterior point of the forehead, AFP1), anterior face P2 (a region of the right cheek, AFP2), anterior face P3 (Pronasal, AFP3), anterior face P4 (a region of the left cheek, AFP4) and anterior face P5 (chin, AFP5) [11] [22] [23]. Neck segment was divided into two point including anterior, posterior and lateral aspects: anterior neck point1 (laryngeal prominence, ANP1) and posterior neck point 1 (the region at the midpoint of occipital protuberance and vertebra prominens, PNP1) [22]. Ear segment was divided into three point including anterior and posterior aspects: anterior ear point 1 (anterior surface of the lobe AEP1), posterior ear point 1 (posterior groove of the concha ridge, PEP1) and posterior ear point 2 (posterior surface of the lobe, PEP2) [24]. Body segment was divided into six point including anterior and posterior aspects: anterior body $\mathrm{P} 1$ (at the midpoint of both acromion process point, ABP1), anterior body P2 (at the midpoint of xiphoid process of sternum and navel, ABP2), anterior body P3 (at midpoint of both ASIS point, ABP3), posterior body P1 (at the midpoint of both superior angle, PBP1), posterior body P2 (at the midpoint of a point located in a midpoint of both inferior angle and a point located in a midpoint of both PSIS, PBP2) and posterior body P3 (at the midpoint of both PSIS point, PBP3) [11]. Upper limb segment was divided into four point including anterior and posterior aspects: anterior upper limb point 1 is a location within the anterior portion of the proximal second of the upper arm (at the midpoint of acromion process and point that is central point of medial and lateral epicondyle, AUP1), anterior upper limb point 2 is a location within the anterior portion of the proximal second of the upper forearm (at the midpoint of a point that is central point of lateral epicondyle and medial epicondyle and a point that is central point of styloid process of radius and ulna, AUP2) (Figure S1) [23] [25]. Posterior upper limb point 1 is a location within the posterior portion of the proximal second of the upper arm (at the midpoint of posterior acromion point and a point that is a center of medial and lateral epicondyle of humerus, PUP1) and posterior upper limb point 2 is a location within the posterior portion of the proximal second of the upper forearm (at the midpoint of medial and lateral epicondyle of humerus and posterior central point of styloid process of radius and ulna, PUP2). Hand segment was divided into seven point including palm and dorsal aspects: dorsal hand point 1 (a central point between $4^{\text {th }}$ metacarpal of head and $5^{\text {th }}$ metacarpal of head, DHP1), dorsal hand point 2 ( $2^{\text {nd }}$ metacarpal of head, DHP2), dorsal point 3 (capitate bone, DHP3), palmar hand point1 ( $2^{\text {nd }}$ metacarpal of head, PHP1), palmar hand point 2 ( $5^{\text {th }}$ metacarpal bone of head, PHP2), palmar hand point 3 ( $1^{\text {st }}$ metacarpal bone of head, PHP3) and palmar hand point 4 (hamate bone, PHP4) (Figure S1) [26]. Lower limb segment was divided into four point including anterior and posterior aspects: anterior lower limb point 1 is a location within the anterior portion of the proximal second of thigh (a greater trochanter and base of patellar, ALP1), anterior lower limb point 2 is a location within the anterior portion of the proximal second of shin (at the midpoint of base of patella and a point that is central point of medial malleolus 
and lateral malleolus, ALP2), posterior lower limb point 1 (at the midpoint of a point that is medial and lateral epicondyle of femur and greater trochanter, PLP1) and posterior lower limb point 2 (at the midpoint of a point that is medial and lateral epicondyle of femur and a point that is medial and lateral malleolus, PLP2) [27]. Foot segment was divided into seven point including sole and dorsal aspects: dorsal foot point 1 ( $4^{\text {th }}$ metatarsal bone of head, DFP1), dorsal foot point 2 ( $1^{\text {st }}$ metatarsal bone of head, DFP2), dorsal foot point 3 (navicular bone, DFP3), sole foot point 1 ( $4^{\text {th }}$ metatarsal bone of head, SFP1), sole foot point $2\left(1^{\text {st }}\right.$ metatarsal bone of head, SFP2), sole foot point 3 (cuboid bone, SFP3) and sole foot point 4 (plantar heel skin, SFP4) (Figure S1) [28] [29]. A Skin Diagnosis Meter (SDM, 2016 BOMTECH ver. 3.20) was used to measure the skin's surface sebum content, moisture, pores, pigmentation, wrinkles, and elasticity on the face, neck, ear, body, upper limb, lower limb, hand, and foot. During the measurement of the skin, the normal fore level was $0.7 \mathrm{~N}$. The same investigator performed all procedures in a room kept at a constant temperature $\left(22^{\circ} \mathrm{C}-24^{\circ} \mathrm{C}\right)$ and humidity $(45 \%-55 \%)$ prior to measurement [11] [22] [23]. The skin testing machine is made up of two meters: the E-cam measures sebum, pigmentation, and pores, and the P-sensor measures moisture and elasticity. The E-cam measures the skin by using an X80 lens, and measures the amount of sebum by using UV light. The meter measures the dermis layer of pigmentation, wrinkle length, and pore size by using general light. The measurement area is in the range of 4 $\mathrm{cm}^{2}$. The P-sensor uses an electrode to send a current on the skin surface and the skin reacts to the electricity. It creates a calculation by using the values of the skin's reaction to the electricity. To measure sebum, the meter uses skin UV to see how much oil is contained in the affected area [24]. To make use of the sebum arbitrary units (SAU), the values are 0 - 650 (a few sebum), 650 - 1200 (normal), 1200 - 5000 (a lot of sebum), and 5000- (excessive sebum). To make use of the moisture arbitrary units (MAU), set the values to $1 \%$ - 100\% [22]. These values are 0 - 19 (very dry), 20 - 29 (dry), 30 - 39 (moderate), 40 - 49 (plenty of moisture), and 50- (a high amount of moisture). The P-sensor meter uses a rectangular spring to measure elasticity. When the spring contacts the skin, it measures how much the sticky part of the spring can be forced into the skin. To make use of the elasticity arbitrary units (EAU), set the values to $1 \%$ $100 \%$ [22] [30]. These values are 0 - 24 (very low elasticity), 25 - 34 (low), 35 - 44 (moderate), 45 - 54 (high), and 55 - (very high), which the values was expressed in graph. The graph area showed skin surface's reactivity value according to distance of measuring part. The data values were measured using Microsoft Office Power Point 2007. Based on the $\mathrm{x}$-axis on 0 to $25.5 \mathrm{~cm}$ and the $\mathrm{y}$-axis on 0 to 20 $\mathrm{cm}$, each coordinate was set on the basis of each vertex of the graph [31] [32]. By connecting the set coordinates, we found the area of the graph. After creating these subdivisions, each vertex of the graph was calculated using the Digital Calipers (Industrial Instrument Company, Mitutoyo, Japan) and the area was calculated using program of the Origin Pro 2016 [33]. The graph of elasticity was 
analyzed by Riemann integration, which the formula for the area is given in equation (Figure S2) [31] [32]. To confirm the measured elasticity data, the Riemann integration was used (Figure S3). Measuring pigmentation is done using the general light [25]. The pigmentation arbitrary units (PiAU) are set at values of 1 - 10 grade, with 0 - 2 (favorable), 2 - 4 (moderate), 4 - 6 (mild), and 6- (severe). To make use of the wrinkle arbitrary units (WAU), set the values to 1 - 10 grade [26]. These are 0 - 2 (favorable), 2 - 3 (early mild wrinkles), 3 - 5 (early severe wrinkles), 5 - 6 (thicker mild wrinkles), and 6- (thicker severe wrinkles). To make use of the pore arbitrary units (PAU), set the values to $1-10$ grade [23]. These are 0 - 2 (small size), 2 - 4 (moderate), 4 - 6 (broadish), 6 - 8 (large), and 8 - (very large).

\subsection{Statistical Analysis}

The IBM SPSS Statistics software (Version 22.0, IBM Corp., Armonk, NY, USA) was used for the statistical analysis. The protocol for this study was approved by the Committee of Ethics in Research of Yong in University in accordance with the terms of Resolution 5-1-20. The data were expressed as mean \pm standard error (SE) of the measurements. A significance level of $\alpha=0.05$ was chosen when performing the independent t-test for comparisons between the sites. Finally, Pearson's correlation coefficients were performed to identify correlations among the variables.

\section{Results}

The sebum content and moisture of the skin's surface varies with body part

The general characteristics were observed healthy Korean men (Table 1). We have summarized the segmentalized data of each body segment in supplementary data (Table S1), which enter the skin condition of each body segment. The sebum content of the men we assessed was relatively close except for the face and neck. The sebum content was high on the face (1306.8 $\pm 104.3 \mathrm{SAU})$ and slightly higher on the neck (173.6 $\pm 37.7 \mathrm{SAU}$ ) (Figure 1(a)). The sebum content of face was demonstrated to be significantly higher than other body parts (Figure 1(a)). The moisture on the face $(53.0 \pm 2.1 \mathrm{MAU})$, hand $(52.9 \pm 1.7$ $\mathrm{MAU})$, and foot $(57.3 \pm 1.5 \mathrm{MAU})$ was significantly higher than on the body $(40.8 \pm 1.4 \mathrm{MAU}$ ) (Figure 1(b)). However, there was no significant difference in moisture among the body parts. The moisture value among them at the foot was relatively higher than at other sites (Figure 1(b)).

The size of the pores on the skin's surface varies with body part

The pore size on the face $(6.0 \pm 0.5 \mathrm{PAU})$ were significantly wider than at other parts, and the pores on the neck $(2.5 \pm 0.3 \mathrm{PAU})$ and lower limb $(1.3 \pm 0.3$ PAU) were wider than at other parts (Figure 2). Furthermore, the value of pore size on the neck and lower limb were significantly increased compared with the ear, respectively (Figure 2).

The wrinkle and pigmentation of the skin's surface varies with body part 


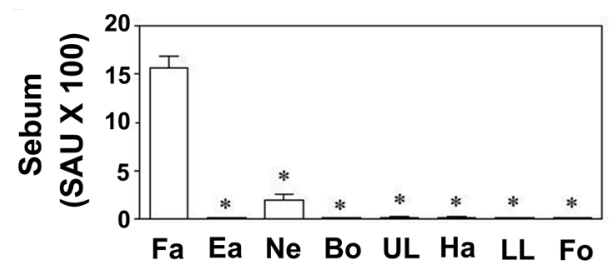

(a)

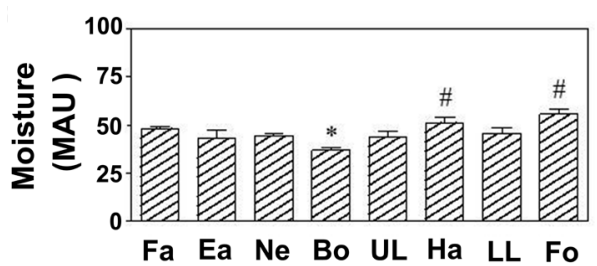

(b)

Figure 1. Differences in the sebum and moisture of the skin's surface for the other body parts. Each bar represents the mean \pm SE. SAU, sebum arbitrary units; MAU, moisture arbitrary units; Fa, face; Ea, ear; Ne, neck; Bo, body; UL, upper limb; Ha, hand; LL, lower limb; Fo, foot. Statistically significant differences exist in Fa vs. Ea, Ne, Bo, UL, Ha, LL, and Fo $\left({ }^{*} p<0.05\right)$, in Bo vs. UL, Ha, LL, and Fo ( $\left.{ }^{*} p<0.05\right)$.
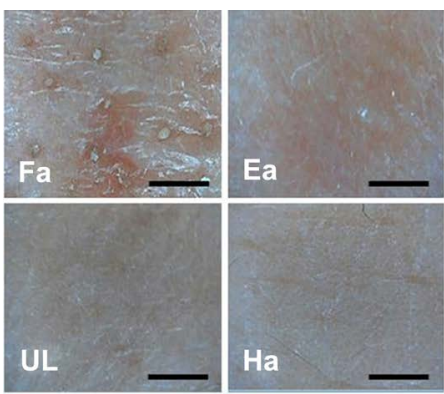
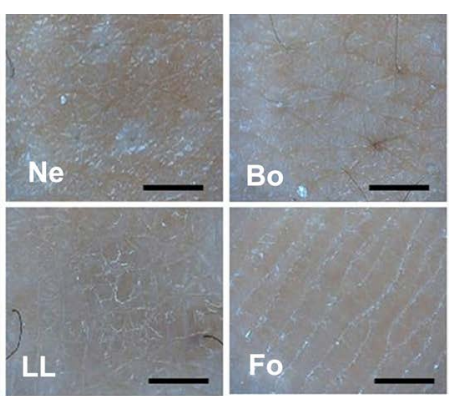

(a)

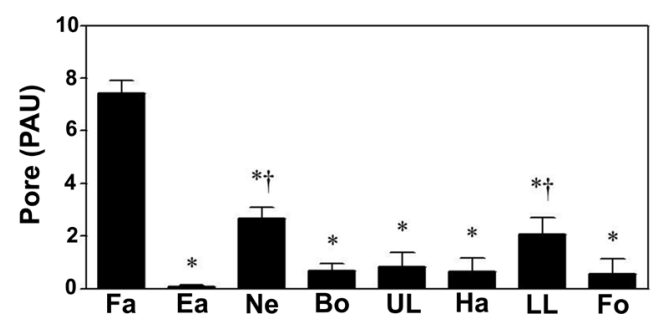

(b)

Figure 2. Differences in the size of pores of the skin's surface for the other body parts. Each bar represents the mean \pm SE. PAU, pore arbitrary units; Fa, face; Ea, ear; Ne, neck; Bo, body; UL, upper limb; Ha, hand; LL, lower limb; Fo, foot. Statistically significant differences exist in Fa vs. Ea, Ne, Bo, UL, Ha, LL, and Fo $\left({ }^{*} p<0.05\right)$, in Ea vs. Ne, Bo, UL, $\mathrm{Ha}, \mathrm{LL}$, and Fo $\left({ }^{\dagger} p<0.05\right)$.

The number of wrinkle of the face $(3.9 \pm 0.2$ WAU) was significantly larger than at other sites, but not neck $(3.7 \pm 0.1 \mathrm{WAU})$ and hand $(3.1 \pm 0.2 \mathrm{WAU})$ (Figure 3(a) and Figure 3(b)). The number of wrinkle of the neck was significantly larger than at other sites, but not face and hand (Figure 3(a) and Figure 3 (b)). Furthermore, the number of wrinkle of the upper limb $(0.7 \pm 0.2 \mathrm{WAU})$ was significantly smaller than at other sites, but not ear $(2.0 \pm 0.2 \mathrm{WAU})$ and lower limb (1.4 $\pm 0.2 \mathrm{WAU}$ ) (Figure 3(a) and Figure 3(b)). Meanwhile, the pigmentation of the face $(3.7 \pm 0.2 \mathrm{PiAU})$ was significantly higher than at other sites, but not neck (4.2 $\pm 0.3 \mathrm{PiAU})$ (Figure 3(a) and Figure 3(c)). The pigmentation of the neck was significantly higher than at other sites, but not the face (Figure 3(a) and Figure 3(c)). Furthermore, the pigmentation of the 


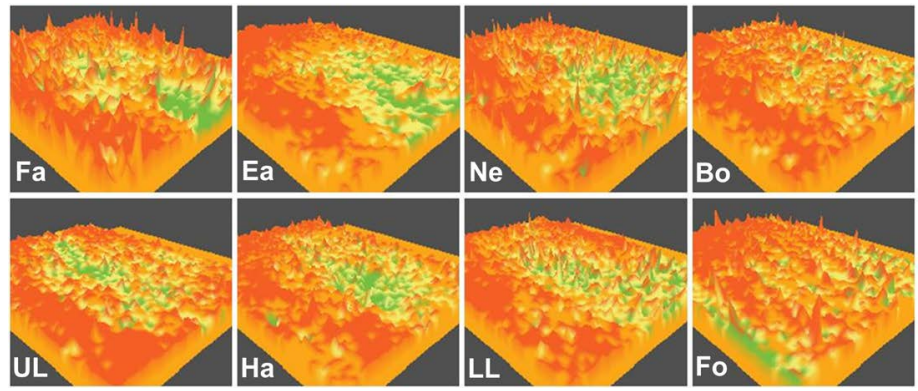

(a)

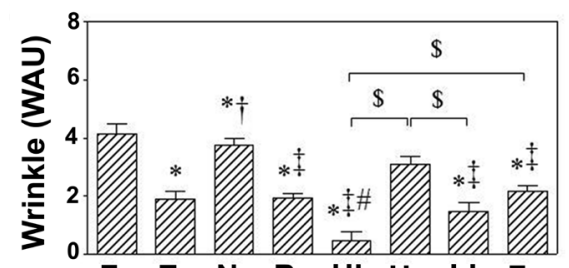

Fa Ea Ne Bo UL Ha LL Fo

(b)

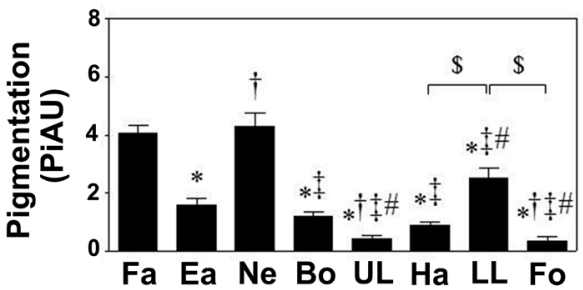

(c)

Figure 3. Differences in the wrinkle and pigmentation of the skin's surface for the other body parts. Each bar represents the mean \pm SE. WAU, wrinkle arbitrary units; PiAU, pigmentation arbitrary units; Fa, face; Ea, ear; Ne, neck; Bo, body; UL, upper limb; Ha, hand; LL, lower limb; Fo, foot. ${ }^{\$} p<0.05$. Statistically significant differences exist in Fa vs. $\mathrm{Ea}, \mathrm{Ne}, \mathrm{Bo}, \mathrm{UL}, \mathrm{Ha}, \mathrm{LL}$, and Fo $\left({ }^{\star} p<0.05\right)$, in Ea vs. Ne, Bo, UL, Ha, LL, and Fo $\left({ }^{\dagger} p<\right.$ $0.05)$, in Ne vs. Bo, UL, Ha, LL, and Fo $\left({ }^{\ddagger} p<0.05\right)$, in Bo vs. UL, Ha, LL, and Fo $\left({ }^{\sharp} p<\right.$ 0.05).

upper limb $(0.6 \pm 0.1 \mathrm{PiAU})$ was significantly lower than at other sites, but not hand $(0.9 \pm 0.1 \mathrm{PiAU})$ and foot $(0.3 \pm 0.1 \mathrm{PiAU})$, respectively (Figure $3(\mathrm{a})$ and Figure 3(c)).

\section{The elasticity of the skin's surface varies with body part}

The elasticity of the face $(52.3 \pm 1.1$ EAU) was significantly higher than at other sites, but not ear (52.4 $\pm 1.3 \mathrm{EAU})$, hand (62.4 $\pm 1.2 \mathrm{EAU})$, and foot $(59.5$ \pm 1.2 EAU), respectively (Figure 4(a) and Figure 4(d)). Furthermore, the elasticity of the upper limb $(35.0 \pm 1.7$ EAU $)$ was significantly lower than at other sites, but not body (36.3 \pm 1.5 EAU) (Figure 4 (a) and Figure 4(d)). To confirm the measured data, we used the integral formula. As a result, given the measured elasticity data, the highest value obtained from the hand (Figure 4(b) and Figure $4(\mathrm{c})$ ), and the highest values was similarly seen at the hands in the value using integral formula (Figure S3). We obtained the matching results from the measured values and values using the integral formula. 


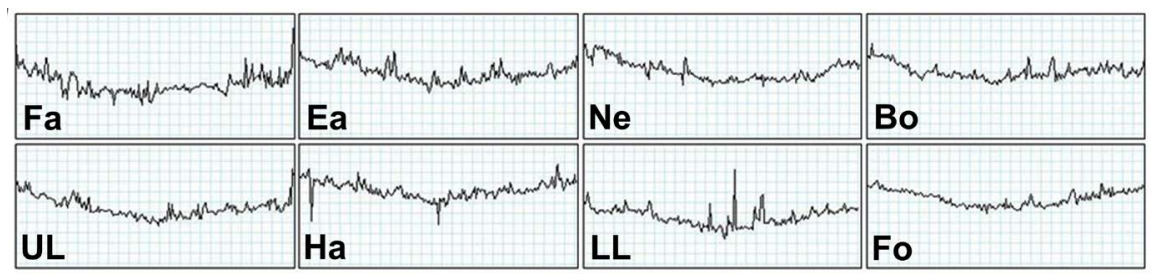

(a)

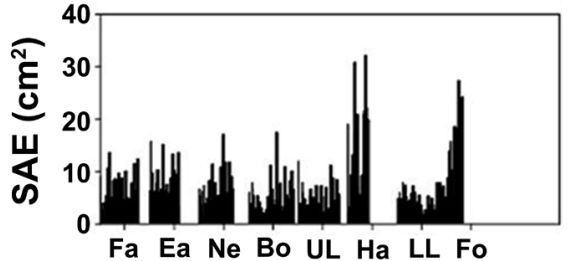

(b)

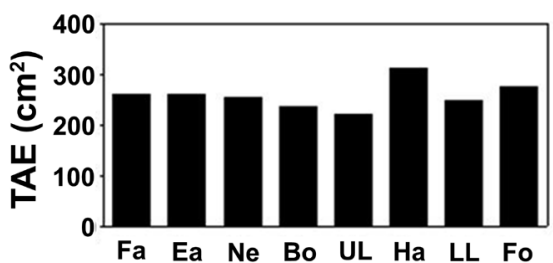

(c)

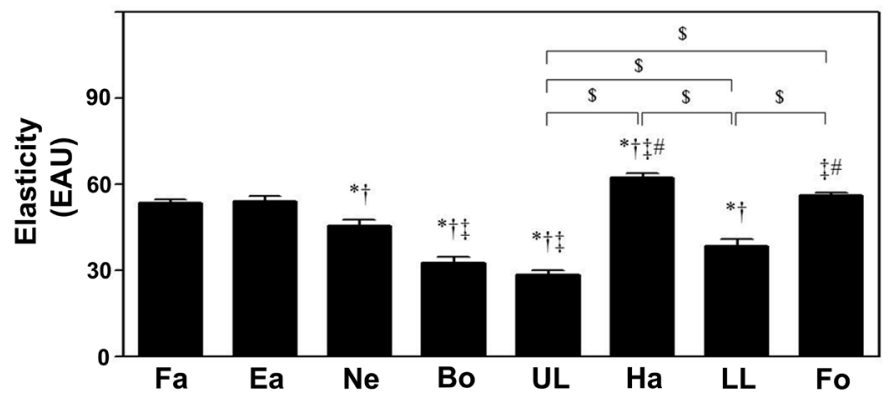

(d)

Figure 4. Differences in the elasticity of the skin's surface for the other body parts. Each bar represents the mean \pm SE. EAU, elasticity arbitrary units; $\mathrm{Fa}$, face; Ea, ear; Ne, neck; Bo, body; UL, upper limb; Ha, hand; LL, lower limb; Fo, foot; SAE and TAE, single and total area of elasticity using the integral formula. ${ }^{\$} p<0.05$. Statistically significant differences exist in Fa vs. Ea, Ne, Bo, UL, Ha, LL, and Fo $\left({ }^{\star} p<0.05\right)$, in Ea vs. Ne, Bo, UL, Ha, LL, and Fo $\left({ }^{\dagger} p<0.05\right)$, in Ne vs. Bo, UL, Ha, LL, and Fo $\left({ }^{\ddagger} p<0.05\right)$, in Bo vs. UL, Ha, LL, and Fo $\left({ }^{\#} p<0.05\right)$.

\section{The correlation of skin conditions among variables}

The Pearson's correlation coefficients among components are shown in Table 2. In this study, the variables; sebum, moisture, pore, wrinkle, pigmentation and elasticity, were classified. All variables input to continuous data. In the correlation analysis results, sebum and pore $(r=0.390, p<0.05)$ were positively correlated, but sebum and moisture $(\mathrm{r}=-0.524, p<0.01)$ and wrinkle and elasticity ( $\mathrm{r}$ $=-0.402, p<0.05)$ were negatively correlated (Table 2 ).

\section{The correlation between sebum and moisture}

The Pearson's correlation coefficients between sebum and moisture on face are shown in Figure 5(a). There were significant correlation between sebum and moisture on face. Among the parts of the body, sebum-moisture values of the face $(r=-0.492, p<0.01)$ were negatively correlated (Figure 5(a)).

The correlation between sebum and pore

The Pearson's correlation coefficients between sebum and pore on face are shown in Figure 5(b). There were significant correlation between sebum and 
Table 2. Pearson's correlation coefficient among skin conditions.

\begin{tabular}{ccccccc}
\hline & Sebum & Moisture & Pore & Wrinkle & Pigmentation & Elasticity \\
\hline Sebum & 1 & & & & & \\
Moisture & $-0.524^{* *}$ & 1 & & & & \\
Pore & $0.390^{*}$ & $-0.469^{* *}$ & 1 & & & \\
Wrinkle & 0.178 & $0.455^{* *}$ & -0.034 & 1 & & \\
Pigmentation & $0.719^{* *}$ & $-0.471^{* *}$ & $0.410^{*}$ & 0.302 & 1 & \\
Elasticity & -0.076 & -0.118 & -0.179 & $-0.402^{*}$ & -.031 & 1 \\
\hline
\end{tabular}

Data presented as Pearson's correlation coefficients. ${ }^{*} p<0.05,{ }^{* *} p<0.01$

\section{Face}

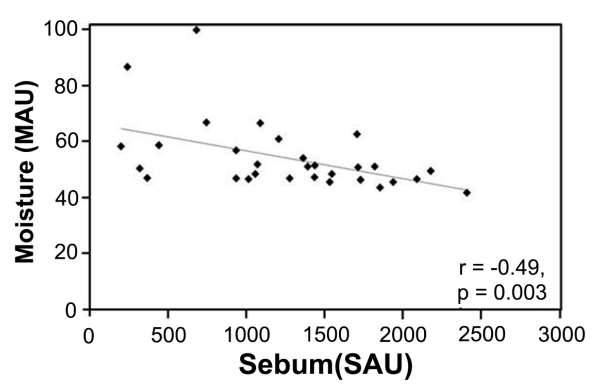

(a)

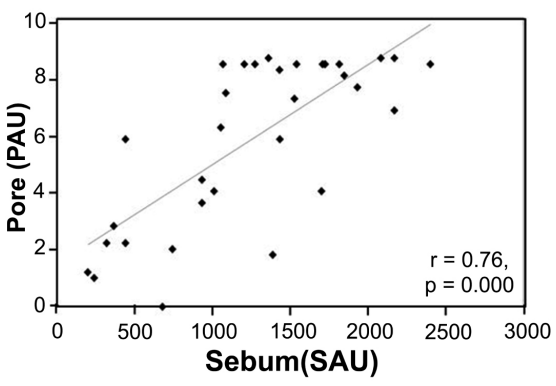

(b)

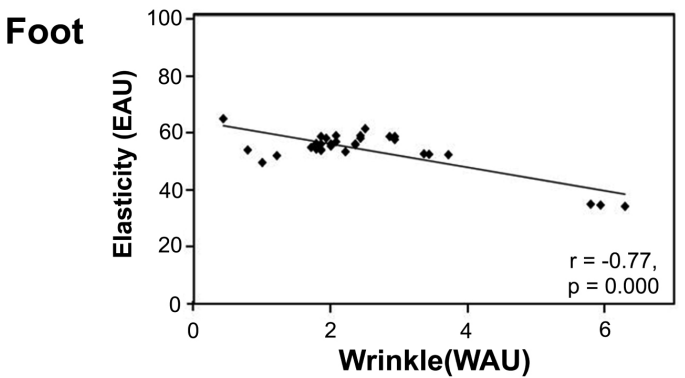

(c)

Figure 5. Correlations among skin conditions from the 20's male at face and foot. MAU, moisture arbitrary units; SAU, sebum arbitrary units; PAU, pore arbitrary units; EAU, elasticity arbitrary units; WAU, wrinkle arbitrary units. (a) \& (b) Face; (b) Foot.

pore on face. Among the parts of the body, sebum-pore values of the face $(\mathrm{r}=$ $0.760, p<0.01$ ) were positively correlated (Figure $5(\mathrm{~b})$ ).

\section{The correlation between wrinkle and elasticity}

The Pearson's correlation coefficients between wrinkle and elasticity on foot are shown in Figure 5(c). There were significant correlation between wrinkle and elasticity on foot. Among the parts of the body, wrinkle-elasticity values of the foot $(\mathrm{r}=-0.773, p<0.01)$ were negatively correlated (Figure $5(\mathrm{c})$ ).

\section{Discussion}

The skin has various factors that protect it from internal factors, such as hormones and temperature, and external irritation, such as tiny particles of dust, air 
and water pollution, human contact, and ultraviolet radiation, which can be influenced by the change in the skin's biophysical properties [1] [2] [4]. This study found that the average values of sebum for the ear, body, upper limb, hand, lower limb, and foot range from 0 to 14.83 , and sebum values are higher at the face and then the neck. This was also reported by mechanism studies of sebum. The sebocyte was affected by both testosterone and $5 \alpha$-DHT, and testosterone controls the sebaceous glands on the face more than those on the upper and lower limb [27]. Moreover, dehydroepiandrosterone levels proceed to a maximum at about 20 years of age in men. Therefore, peak sebum content occurs in the 20 year age group in men [28]. In another study, Pochi reported that the development and secretory activity of men's sebaceous glands is influenced by hormonal factors [10]. Sato reported that androgenic steroids, particularly of gonadal origin, are the hormones principally responsible for these effects and the only ones shown to have a direct stimulatory effect on glandular activity [29]. Therefore, face sebum content is higher than at other sites. This means that men in their 20 $s$ are greatly influenced by hormones, so sebum values are higher in the face and neck. As a result, men should pay attention to skin care and use appropriate skin products thoughtfully. The present study demonstrates that the average values of skin moisture for the face, ear, neck, body, upper limb, and lower limb range from 34.73 to 46.91 . Moisture values are higher in the hand and foot. Previous studies have demonstrated that higher water evaporation in the hand is caused [9]. As the parts of the body that move the most, muscular contraction during activity elevates the temperature of the skin and the sweat rate [34]. Because eccrine glands is known that are found mainly on the palm, soles, and maxillary region [35]. On the other hand, as negative effects are caused by external factors, the depletion or disturbance of the major lipids in the SC that can be caused by dry air is thought to be one of the etiological factors producing dryness and barrier disruption in skin conditions [2]. This means that when a person is in the sunlight for a long time, water evaporation on the skin is severe and sunburns and photoaging are caused [36]. The results of this study show that moisture is higher in the hands and feet than in other areas, so the differences between each body part are considered to be differences in the distribution of the eccrine glands. Some studies have reported that pigmented skin and melanin damage are caused by ultraviolet radiation, which causes photochemical reactions. This affects the keratogenesis in the basal layer cell activity, making UVA active [37] [38]. The most important physiological function of all from the outside of the epidermal surface serves as a backstop of stimulus, or of the stratum corneum to build up the skin, of which exposure to sunlight's ultraviolet radiation creates a thick layer of stratum corneum to make the role of external stimulation [39]. Thus, the thicker the stratum corneum, sebaceous gland and irritation may occur as in, this part occurs that is released in acne and can be formed easily [40]. Enjoying outdoor activities outside of elite sports includes exposure of 10 to 20 units of UVB. Therefore, as the face is highly exposed to sunlight, the pigmentation rate is higher than in other areas. On the other hand, the pigmentation rate 
of the upper limb area is not high. In view of the use of sunscreen by Koreans, many of them use it on the face, neck, and upper limbs. Our results show a high pigment rate on the face, neck, thigh, and shin, which are frequently exposed to sunlight. However, the face and upper limbs are often protected by sunscreen usage, because many people use sunscreen in those areas. Sunscreen is used less on the thighs and shins, so in Korea, men in their 20s express a high pigmentation rate in these areas. Due to wearing long sleeves and using a sunscreen blocker on upper limbs, this skin has a low pigmentation rate [13] [41]. The distribution of sebaceous glands is high on the face and scalp. A study reported that the distribution of sebum among men and women is likely quite different because it is affected by hormones and hormone levels due to activity and nature [42]. Men in their $20 \mathrm{~s}$ have the most abundant amount of sebum, so they will be susceptible to skin diseases [10]. Studies have shown that hormonal effects are a big part of the consequences that a big factor. There is considered to be a correlation between sebum and pores. As sebum increases, research has shown that the pores increase in size [9] [11]. Our results show that face sebum and pores are higher than in other areas and that there is a correlation between sebum and pores. Our results and pilot studies get to know that it is no difference. The UV radiation consists of UVA (320 - $400 \mathrm{~nm})$, UVB (280 - $320 \mathrm{~nm})$, and UVC (200 $280 \mathrm{~nm}$ ) [15]. Of these three types of UV radiation, UVA and UVB include the highest amount of energy, resulting mainly in photoaging [43]. The characteristics of UVB primarily affect the epidermal layer, where a large proportion of UVB is absorbed [44]. This causes side effects in the DNA of keratinocytes and melanocytes, and induces the production of inflammatory cytokines and proteolytic enzymes, leading to the destruction of collagen and elastin [37]. The characteristics of UVA penetrate more deeply into the dermis and damage the epidermis and dermis more than UVB. Another side effect of UV radiation at the cellular level is the accumulation of reactive oxygen species (ROS) through a complex cascade of biochemical reactions in the human skin [38]. UV-induced pro-inflammatory cytokines, oxidative stress, and loss of antioxidant enzymes cause the destruction of collagen in skin tissue, leading to wrinkle formation. The results of this study showed that face, neck, and lower limb values were higher than in other sites. However, the face and neck are almost constantly exposed to the sun's rays in comparison with the lower limbs. Some studies have reported that elastic fiber density is in accordance with the electrical stimulus period expires, tend to grow. And increasing elastic fiber density by electrical impulses results from fibroblast activation by electrical impulses, as well as collagen type I [45]. The previous results by Guler reported that electric stimulation increased connective tissue [46]. Another study reported that UV irradiation impairs TGF-beta 1, reduces type I procollagen production by fibroblasts in human skin [47]. Our study found that elasticity in the hands and feet is higher than in other areas. In the above study comparison, electrical impulses increased collagen and skin elasticity. We do a lot of work using our hands, and always walk on our feet. So, to increase the density of many parts of the stimulus, skin 
elasticity will increase the elasticity, as well as collagen. According to the correlation analysis, the sebum and pore were positively correlated. In a previous study, similar correlations were found among the variables. For example, Roh et al. performed a correlation analysis, the sebum and pore, the results were that the sebum output level correlated most significantly with the pore size [11]. A study showed a positive relationship between sebum and pore. Our study showed that sebum and pore positively relates in Korean's male. A study by Khan showed that cream containing Ficus carica increased the skin hydration, and sebum was decreased [48]. Other study of facial photoaing skin in patients showed that the sebum was increased, and hydration was decreased in patients affected by photoaing. In this study, its data showed that a difference values between sebum and hydration [49]. According to the correlation analysis, in our data, the sebum and moisture were negatively correlated. Although this study is concentrated on the patient, our data could be a big indicator for general adult. According to the correlation analysis, the wrinkle and elasticity were negatively correlated. In previous study, As a result, aloe decreased wrinkles and it increased elasticity in patients with an increase of the net procollagen [19]. Although our data focuses on normal skin conditions, this data could be a barometer of other studies. The data in this study provides index for a whole body skin condition in terms of the health male.

\section{Conclusion}

For nearly the first time, this study resulted in systematic reference values for standardized biophysical measuring methods and body parts reflecting the skin physiology of men. The results show that skin's surface sebum, moisture, pores, wrinkles, pigmentation, and elasticity vary with the part of the body.

\section{Acknowledgements}

We thank to the Yongin University students for supporting this work. There are actively supported by Dan-Ho academy.

\section{References}

[1] Proksch, E., Brandner, J.M. and Jensen, J.M. (2008) The Skin: An Indispensable Barrier. Experimental Dermatology, 17, 1063-1072. https://doi.org/10.1111/j.1600-0625.2008.00786.x

[2] Sahle, F.F., et al. (2015) Skin Diseases Associated with the Depletion of Stratum Corneum Lipids and Stratum Corneum Lipid Substitution Therapy. Skin Pharmacology and Physiology, 28, 42-55. https://doi.org/10.1159/000360009

[3] Morita, A., Torii, K., Maeda, A. and Yamaguchi, Y. (2009) Molecular Basis of Tobacco Smoke-Induced Premature Skin Aging. Journal of Investigative Dermatology Symposium Proceedings, 14, 53-55. https://doi.org/10.1038/jidsymp.2009.13

[4] Reed, J.T., Elias, P.M. and Ghadially, R. (1997) Integrity and Permeability Barrier Function of Photoaged Human Epidermis. Archives of Dermatology, 133, 395-396. https://doi.org/10.1001/archderm.1997.03890390139031

[5] Firooz, A., et al. (2007) Comparsion of Hydration, Sebum and pH Values in Clini- 
cally Normal Skin of Patients with Atopic Dermatitis and Healthy Controls. Clinical and Experimental Dermatology, 32, 321-322.

https://doi.org/10.1111/j.1365-2230.2007.02364.x

[6] Sator, P.G., Schmidt, J.B. and Hönigsmann, H. (2003) Comparsion of Epidermal Hydration and Skin Surface Lipids in Healthy Individuals and in Patients with Atopic Dermatitis. Journal of the American Academy of Dermatology, 48, 352-358. https://doi.org/10.1067/mjd.2003.105

[7] Gupta, J., et al. (2008) Intrinsically Defective Skin Barrier Function in Children with Atopic Dermatitis Correlates with Disease Severity. Journal of Allergy and Clinical Immunology, 121, 725-730. https://doi.org/10.1016/j.jaci.2007.12.1161

[8] Tomita, Y., Akiyama, M. and Shimizu, H. (2005) Stratum Corneum Hydration and Flexibility Are Useful Parameters to Indicate Clinical Severity of Congenital Ichthyosis. Experimental Dermatology, 14, 619-624. https://doi.org/10.1111/j.0906-6705.2005.00341.x

[9] Luebberding, S., Krueger, N. and Kerscher, M. (2014) Age-Related Changes in Male Skin: Quantitative Evaluation of One Hundred and Fifty Male Subjects. Skin Pharmacology and Physiology, 27, 9-17. https://doi.org/10.1159/000351349

[10] Pochi, P.E. and Strauss, J.S. (1974) Endocrinologic Control of the Development and Activity of the Human Sebaceous Gland. Journal of Investigative Dermatology, 62, 191-201. https://doi.org/10.1111/1523-1747.ep12676783

[11] Roh, M., Han, M., Kim, D. and Chung, K. (2006) Sebum Output as a Factor Contributing to the Size of Facial Pores. British Journal of Dermatology, 155, 890-894. https://doi.org/10.1111/j.1365-2133.2006.07465.x

[12] Lawler, S., et al. (2012) Relationships of Sun-Protection Habit Strength with Sunscreen Use during Outdoor Sport and Physical Activity. International Journal of Environmental Research and Public Health, 9, 916-923. https://doi.org/10.3390/ijerph9030916

[13] Holman, D.M., et al. (2015) Patterns of Sunscreen Use on the Face and Other Exposed Skin among US Adults. Journal of the American Academy of Dermatology, 73, 83-92. https://doi.org/10.1016/j.jaad.2015.02.1112

[14] Holick, M.F. (2016) Biological Effects of Sunlight, Ultraviolet Radiation, Visible Light, Infrared Radiation and Vitamin D for Health. Anticancer Research, 36, 1345-1356.

[15] Hockberger, P.E. (2002) A History of Ultraviolet Photobiology for Humans, Animals and Microorganisms. Photochemistry and Photobiology, 76, 561-579.

[16] Zastrow, L., et al. (2009) The Missing Link-Light-Induced (280 - $1600 \mathrm{~nm}$ ) Free Radical Formation in Human Skin. Skin Pharmacology and Physiology, 22, 31-44. https://doi.org/10.1159/000188083

[17] Seckmeyer, G., Mayer, B., Erb, R. and Bernhard, G. (1994) UV-B in Germany Higher in 1993 than in 1992. Geophysical Research Letters, 21, 577-580. https://doi.org/10.1029/94GL00567

[18] Sulcová, J., Hill, M., Hampl, R. and Stárka, L. (1997) Age and Sex Related Differences in Serum Levels of Unconjugated Dehydroepiandrosterone and Its Sulphate in Normal Subjects. Journal of Endocrinology, 154, 57-62. https://doi.org/10.1677/joe.0.1540057

[19] Cho, S., et al. (2009) Dietary Aloe vera Supplementation Improves Facial Wrinkles and Elasticity and It Increases the Type I Procollagne Gene Expression in Human Skin in Vivo. Annals of Dermatology, 21, 6-11. 
https://doi.org/10.5021/ad.2009.21.1.6

[20] Thompson, J.E. (1991) Topical Use of Aloe vera Derived Allantoin Gel in Otolaryngology. Ear, Nose \& Throat Journal, 70, 119.

[21] Kim, S.I., et al. (2015) Distribution of Serum Bisphenol A Diglycidyl Ether and Its Metabolite in Korean Adult Men and Its Association with Reproductive Hormone Levels. Molecular \& Cellular Toxicology, 11, 71-78. https://doi.org/10.1007/s13273-015-0009-3

[22] Bertuccelli, G., et al. (2016) Effect of a Quality-Controlled Fermented Nutraceutical on Skin Aging Markers: An Antioxidant-Control, Double-Blind Study. Experimental and Therapeutic Medicine, 11, 909-916. https://doi.org/10.3892/etm.2016.3011

[23] Lee, B.M., et al. (2015) Topical Application of a Cleanser Containing Extracts of Diospyros kaki folium, Polygonum cuspidatum and Castanea crenata var. dulcis Reduces Skin Oil Content and Pore Size in Human Skin. Biomedical Reports, 3, 343-346. https://doi.org/10.3892/br.2015.435

[24] Ezerskaia, A., et al. (2016) Quantitative and Simultaneous Non-Invasive Measurement of Skin Hydration and Sebum Levels. Biomedical Optics Express, 7, 2311-2320. https://doi.org/10.1364/BOE.7.002311

[25] Wang, F., et al. (2008) Effect of Increased Pigmentation on the Antifibrotic Response of Human Skin to UV-A1 Phototherapy. Archives of Dermatology, 144, 851-858. https://doi.org/10.1001/archderm.144.7.851

[26] Fu, J.J., et al. (2010) A Randomized, Controlled Comparative Study of the Wrinkle Reduction Benefits of a Cosmetic Niacinamide/Peptide/Retinyl Propionate Product Regimen vs. a Prescription 0.02\% Tretinoin Product Regimen. British Journal of Dermatology, 162, 647-654. https://doi.org/10.1111/j.1365-2133.2009.09436.x

[27] Akamatsu, H., Zouboulis, C.C. and Orfanos, C.E. (1992) Control of Human Sebocyte Proliferation in Vitro by Testosterone and 5-Alpha-Dihydrotestosterone Is Dependent on the Localization of the Sebaceous Glands. Journal of Investigative Dermatology, 99, 509-511.

[28] Man, M.Q., et al. (2009) Variation of Skin Surface pH, Sebum Content and Stratum Corneum Hydration with Age and Gender in a Large Chinese Population. Skin Pharmacology and Physiology, 22, 190-199. https://doi.org/10.1159/000231524

[29] Sato, K., Kang, W.H., Saga, K. and Sato, K.T. (1989) Biology for Sweat Glands and Their Disorders. I. Normal Sweat Gland Function. Journal of the American Academy of Dermatology, 20, 537-563. https://doi.org/10.1016/S0190-9622(89)70063-3

[30] Lee, H., et al. (2016) Chloroform Induces Cystein-Rich 61, a Mediator of Collagen Homeostasis via Early Growth Response-1 Dependent Pathway in Human Skin Dermal Fibroblasts. Molecular \& Cellular Toxicology, 12, 337-343. https://doi.org/10.1007/s13273-016-0038-6

[31] Guseinov, G.S. (2003) Integration on Time Scales. Journal of Mathematical Analysis and Applications, 285, 107-127. https://doi.org/10.1016/S0022-247X(03)00361-5

[32] Toh, T.L. and Chew, T.S. (2003) The Riemann Approach to Stochastic Integration Using Non-Uniform Meshes. Journal of Mathematical Analysis and Applications, 280, 133-147. https://doi.org/10.1016/S0022-247X(03)00059-3

[33] Aksornmuang, J., Nakajima, M., Foxton, R.M. and Tagami, J. (2007) Mechanical Properties and Bond Strength of Dual-Cure Resin Composites to Root Canal Dentin. Dental Materials, 23, 226-234. https://doi.org/10.1016/j.dental.2006.01.014

[34] Shibasaki, M. and Crandall, C.G. (2010) Mechanisms and Controllers of Eccrine Sweating in Humans. Frontiers in Bioscience, 2, 685-696. 
[35] Callejas, M.A., Grimalt, R. and Cladellas, E. (2010) Hyperhydrosis Update. Actas Dermo-Sifiliográficas, 101, 110-118. https://doi.org/10.1016/j.ad.2009.09.004

[36] Kluschke, F., et al. (2014) Gain or Loss? Sunscreen Efficiency after Cosmetic Pretreatment of the Skin. Skin Pharmacology and Physiology, 27, 82-89.

https://doi.org/10.1159/000351549

[37] Burke, K.E. and Wei, H. (2009) Synergistic Damage by UVA Radiation and Pollutants. Toxicology and Industrial Health, 25, 219-224. https://doi.org/10.1177/0748233709106067

[38] Pillai, S., Oresajo, C. and Hayward, J. (2005) Ultraviolet Radiation and Skin Aging: Roles of Reactive Oxygen Species, Inflammation and Protease Activation, and Strategies for Prevention of Inflammation-Induced Matrix Degradation-A Review. International Journal of Cosmetic Science, 27, 17-34. https://doi.org/10.1111/j.1467-2494.2004.00241.x

[39] Imokawa, G. (2009) Mechanism of UVB-Induced Wrinkling of the Skin: Paracrine Cytokine Linkage between Keratinocytes and Fibroblasts Leading to the Stimulation of Elastase. Journal of Investigative Dermatology Symposium Proceedings, 14, 36-43. https://doi.org/10.1038/jidsymp.2009.11

[40] Aslam, I., Fleischer, A. and Feldman, S. (2015) Emerging Drugs for the Treatment of Acne. Expert Opinion on Emerging Drugs, 20, 91-101. https://doi.org/10.1517/14728214.2015.990373

[41] Hemminki, K., Bykov, V.J. and Marcusson, J.A. (1999) Re: Sunscreen Use and Duration of Sun Exposure: A Double-Blind, Randomized Trial. Journal of the National Cancer Institute, 91, 2046-2047. https://doi.org/10.1093/jnci/91.23.2046

[42] Thiboutot, D. (2004) Regulation of Human Sebaceous Glands. Journal of Investigative Dermatology, 123, 1-12. https://doi.org/10.1111/j.1523-1747.2004.t01-2-.x

[43] Bernerd, F., Marionnet, C. and Duval, C. (2012) Solar Ultraviolet Radiation Induces Biological Alterations in Human Skin in Vitro: Relevance of a Well-Balanced UVA/UVB Protection. Indian Journal of Dermatology, Venereology and Leprology, 78, 15-23. https://doi.org/10.4103/0378-6323.97351

[44] Rijken, F., Bruijnzeel, P.L., van Weelden, H. and Kiekens, R.C. (2004) Responses of Black and White Skin to Solar-Simulating Radiation: Differences in DNA Photodamage, Infiltrating Neutrophils, Proteolytic Enzymes Induced, Keratinocyte Activation, and IL-10 Expression. Journal of Investigative Dermatology, 122, 1448-1455. https://doi.org/10.1111/j.0022-202X.2004.22609.x

[45] Ignotz, R.A. and Massagué, J. (1986) Transforming Growth Factor-Beta Stimulates the Expression of Fibronectin and Collagen and Their Incorporation into the Extracellular Matrix. The Journal of Biological Chemistry, 261, 4337-4345.

[46] Güler, G., Atalay, N.S., Ozoğul, C. and Erdoğan, D. (1996) Biochemical and Structural Approach to Collagen Synthesis under Electric Fields. General Physiology and Biophysics, 15, 429-440.

[47] Quan, T., et al. (2004) Solar Ultraviolet Irradiation Reduces Collagen in Photoaged Human Skin by Blocking Transforming Growth Factor-Beta Type II Receptor/Smad Signaling. American Journal of Pathology, 165, 741-751. https://doi.org/10.1016/S0002-9440(10)63337-8

[48] Khan, H., Akhter, N. and Ali, A. (2014) Effects of Cream Containing Ficus carica L. Fruit Extract on Skin Parameters: In Vivo Evaluation. Indian Journal of Pharmaceutical Sciences, 76, 560-564.

[49] Di Cerb, A., Laurino, C., Palmieri, B. and Iannitti, T. (2015) A Dietary Supplement 
Improves Facial Photoaging and Skin Sebum, Hydration and Tonicity Modulating Serum Fibronectin, Neutrophil Elastase 2, Hyaluronic Acid and Carbonylated Proteins. Journal of Photochemistry and Photobiology B: Biology, 144, 94-103.

https://doi.org/10.1016/j.jphotobiol.2014.12.025 


\section{Appendix}

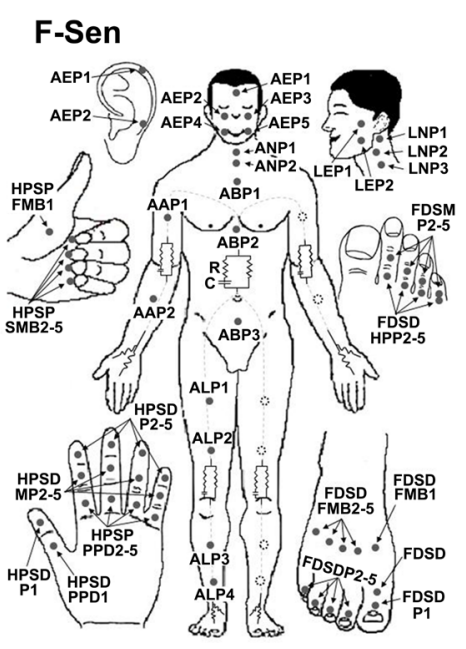

(a)

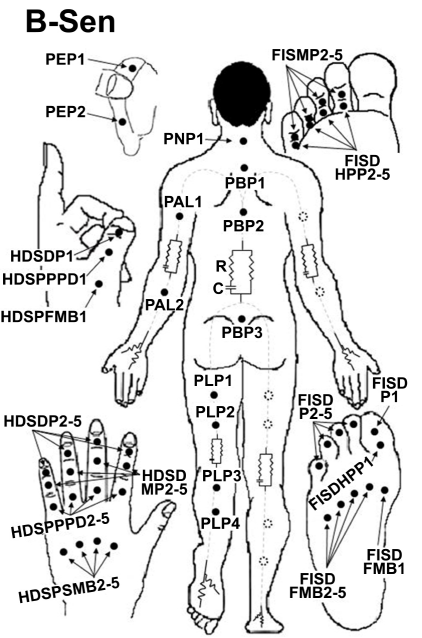

(b)

Figure S1. Schematic representation of the experimental methods for measuring body composition and tactile sensation. Tactile sensation and body composition were determined, as described in Methods section and Table 2. R and C, resistance and condenser of electrical circuit of the total body; (a) F-Sen, sensation of front of the body; (b) B-Sen, sensation of back of the body.

$$
\int_{b}^{a} \cdot f(t) \Delta t=\int_{b}^{a} \cdot f(t) d t(1)
$$

Figure S2. Schematic representation of the equation of Riemann integration for measuring skin elasticity.

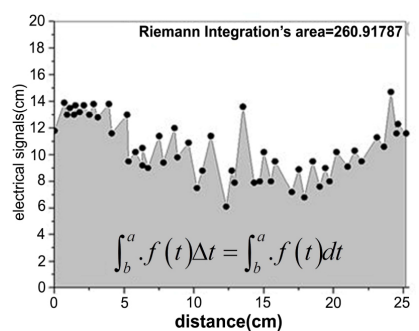

(a)

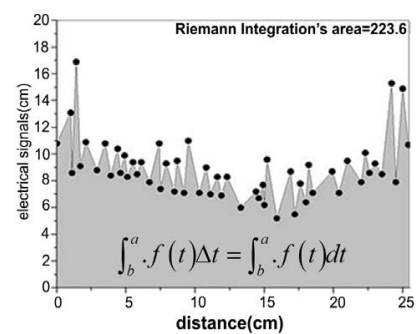

(e)

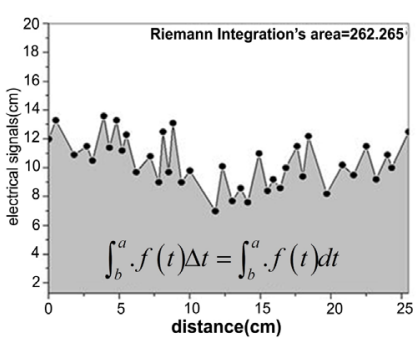

(b)

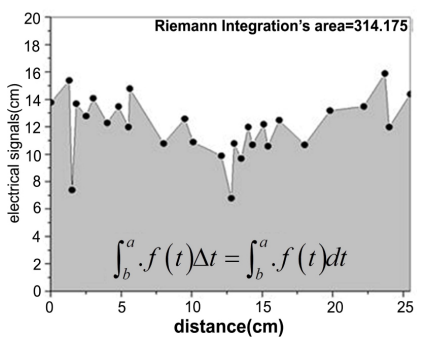

(f)

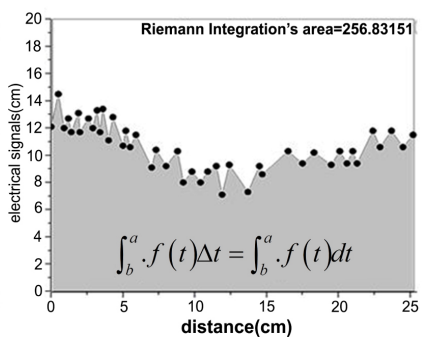

(c)

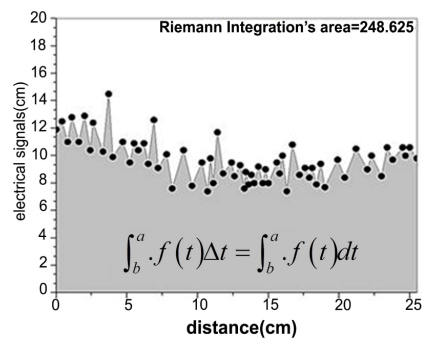

(g)

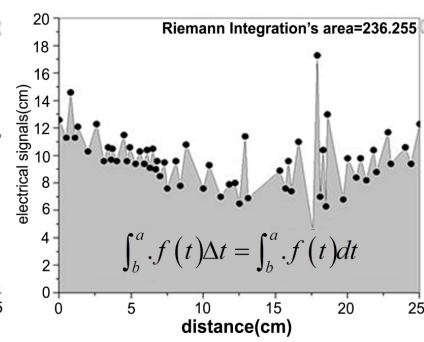

(d)

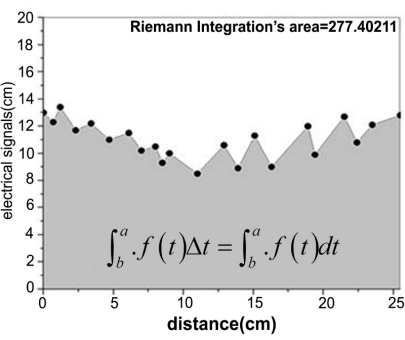

(h)

Figure S3. Analysis of the elasticity using integral formula of the skin's surface for the other body parts. The elasticity was determined, as described in Methods section. (a) Face; (b) Ear; (c) Neck; (d) Body; (e) Upper Limb; (f) Hand; (g) Lower Limb; (h) Foot. 
Table S1. Differences in the skin condition for the other body parts.

\begin{tabular}{|c|c|c|c|c|c|c|}
\hline & Sebum & Moisture & Pore & Wrinkle & Pigmentation & Elasticity \\
\hline Face P1 & $1831.6 \pm 231.2$ & $54.3 \pm 2.3$ & $5.4 \pm 0.5$ & $3.8 \pm 0.2$ & $2.4 \pm 0.2$ & $55.3 \pm 1.3$ \\
\hline $\mathrm{P} 2$ & $1041.4 \pm 117.3^{*}$ & $54.9 \pm 2.1$ & $6.0 \pm 0.5$ & $3.9 \pm 0.3$ & $4.1 \pm 0.3^{\star}$ & $54.8 \pm 2.0$ \\
\hline P3 & $1301.2 \pm 137.2$ & $50.1 \pm 2.2$ & $5.6 \pm 0.5$ & $3.3 \pm 0.3$ & $3.8 \pm 0.3^{*}$ & $51.0 \pm 1.3^{*}$ \\
\hline $\mathrm{P} 4$ & $901.9 \pm 94.8^{* \ddagger}$ & $51.6 \pm 2.3$ & $5.7 \pm 0.5$ & $3.7 \pm 0.3$ & $4.0 \pm 0.4^{*}$ & $51.0 \pm 2.2$ \\
\hline P5 & $1153.3 \pm 124.5^{\star}$ & $54.9 \pm 2.2$ & $6.8 \pm 0.5$ & $4.2 \pm 0.3$ & $3.6 \pm 0.2^{*}$ & $50.8 \pm 1.6^{*}$ \\
\hline Ear ARtP1 & $2.6 \pm 1.5$ & $48.7 \pm 3.5$ & $0.2 \pm 0.1$ & $2.6 \pm 0.2$ & $1.5 \pm 0.2$ & $51.5 \pm 1.5$ \\
\hline ALtP1 & $0.0 \pm 0.0$ & $45.4 \pm 3.5$ & $0.0 \pm 0.0$ & $1.9 \pm 0.3^{*}$ & $1.2 \pm 0.1$ & $51.4 \pm 1.4$ \\
\hline PRtP1 & $31.4 \pm 7.9$ & $42.5 \pm 2.6$ & $0.0 \pm 0.0$ & $2.9 \pm 0.2$ & $1.1 \pm 0.2$ & $51.6 \pm 2.1$ \\
\hline PRtP2 & $16.3 \pm 2.9$ & $43.9 \pm 3.0$ & $0.1 \pm 0.0$ & $3.4 \pm 0.4$ & $0.6 \pm 0.2$ & $55.7 \pm 2.6$ \\
\hline PLtP1 & $53.9 \pm 28.4$ & $43.7 \pm 2.3$ & $0.0 \pm 0.0$ & $0.6 \pm 0.2^{* \dagger}$ & $1.3 \pm 0.1$ & $50.7 \pm 1.5$ \\
\hline Neck AP1 & $306.1 \pm 74.5$ & $49.1 \pm 1.4$ & $2.7 \pm 0.4$ & $3.8 \pm 0.2$ & $4.5 \pm 0.3$ & $50.0 \pm 2.4$ \\
\hline PP1 & $117.7 \pm 37.4^{*}$ & $46.8 \pm 2.4$ & $2.1 \pm 0.2$ & $3.5 \pm 0.3$ & $4.1 \pm 0.3$ & $47.2 \pm 2.0$ \\
\hline UL ARtP1 & $0.0 \pm 0.0$ & $50.3 \pm 2.2$ & $0.7 \pm 0.3$ & $0.6 \pm 0.3$ & $0.6 \pm 0.1$ & $38.9 \pm 2.3$ \\
\hline ARtP2 & $0.0 \pm 0.0$ & $51.6 \pm 2.1$ & $0.6 \pm 0.3$ & $0.5 \pm 0.2$ & $0.6 \pm 0.1$ & $37.6 \pm 2.5$ \\
\hline ALtP1 & $0.0 \pm 0.0$ & $44.4 \pm 1.9^{*}$ & $0.4 \pm 0.3$ & $0.7 \pm 0.2$ & $0.5 \pm 0.1$ & $34.2 \pm 2.0$ \\
\hline ALtP2 & $0.0 \pm 0.0$ & $43.9 \pm 2.1^{\star}$ & $0.3 \pm 0.3$ & $0.6 \pm 0.2$ & $0.4 \pm 0.1$ & $33.7 \pm 2.3$ \\
\hline PRtP1 & $0.0 \pm 0.0$ & $50.6 \pm 3.1$ & $0.7 \pm 0.3$ & $0.4 \pm 0.2$ & $0.4 \pm 0.1$ & $34.6 \pm 1.8$ \\
\hline PRtP2 & $0.0 \pm 0.0$ & $51.6 \pm 2.3$ & $0.6 \pm 0.3$ & $0.8 \pm 0.4$ & $1.0 \pm 0.3$ & $33.4 \pm 1.8$ \\
\hline PLtP1 & $0.0 \pm 0.0$ & $46.0 \pm 2.7$ & $0.4 \pm 0.3$ & $1.0 \pm 0.3$ & $0.6 \pm 0.1$ & $35.4 \pm 2.2$ \\
\hline PLtP2 & $0.0 \pm 0.0$ & $47.1 \pm 3.0$ & $0.3 \pm 0.3$ & $0.6 \pm 0.3$ & $0.9 \pm 0.2$ & $37.2 \pm 2.4$ \\
\hline Hand PaRtP1 & $2.1 \pm 1.5$ & $52.9 \pm 2.3$ & $0.3 \pm 0.3$ & $4.0 \pm 0.3$ & $0.9 \pm 0.3$ & $65.8 \pm 2.0$ \\
\hline PaRtP3 & $0.0 \pm 0.0$ & $53.5 \pm 1.8$ & $0.3 \pm 0.3$ & $4.5 \pm 0.4$ & $0.8 \pm 0.2$ & $65.3 \pm 1.7$ \\
\hline PaRtP4 & $30.9 \pm 21.5$ & $55.9 \pm 1.7$ & $0.3 \pm 0.3$ & $3.9 \pm 0.4$ & $0.4 \pm 0.1^{\dagger}$ & $64.3 \pm 2.3$ \\
\hline PaLtP1 & $0.0 \pm 0.0$ & $57.9 \pm 2.4$ & $0.3 \pm 0.3$ & $4.5 \pm 0.3$ & $0.5 \pm 0.1^{\dagger}$ & $63.6 \pm 2.5$ \\
\hline PaLtP2 & $0.0 \pm 0.0$ & $58.3 \pm 1.6$ & $0.3 \pm 0.3$ & $4.7 \pm 0.3$ & $0.3 \pm 0.1^{\dagger}$ & $62.4 \pm 2.4$ \\
\hline PaLtP3 & $0.0 \pm 0.0$ & $58.4 \pm 2.3^{\ddagger}$ & $0.3 \pm 0.3$ & $3.8 \pm 0.3^{\$}$ & $0.8 \pm 0.1$ & $57.9 \pm 2.2^{\star+\neq}$ \\
\hline PaLtP4 & $0.0 \pm 0.0$ & $60.4 \pm 2.2^{\star \dagger \dagger}$ & $0.3 \pm 0.3$ & $4.2 \pm 0.3$ & $0.7 \pm 0.1$ & $65.8 \pm 2.6^{\&}$ \\
\hline DRtP1 & $5.5 \pm 5.5$ & $52.7 \pm 2.6$ & $0.1 \pm 0.1$ & $1.2 \pm 0.2$ & $1.6 \pm 0.2$ & $53.1 \pm 1.2$ \\
\hline DRtP2 & $0.0 \pm 0.0$ & $47.3 \pm 2.7$ & $0.3 \pm 0.3$ & $2.0 \pm 0.3^{*}$ & $1.6 \pm 0.2$ & $59.0 \pm 1.8^{\star}$ \\
\hline DRtP3 & $0.0 \pm 0.0$ & $46.0 \pm 2.5$ & $0.4 \pm 0.3$ & $1.6 \pm 0.2$ & $0.9 \pm 0.2^{* \dagger}$ & $49.8 \pm 1.7^{\dagger}$ \\
\hline DLtP1 & $0.0 \pm 0.0$ & $51.6 \pm 2.7$ & $0.5 \pm 0.3$ & $1.5 \pm 0.2$ & $0.4 \pm 0.1^{\star \dagger \ddagger}$ & $52.4 \pm 1.4^{\dagger}$ \\
\hline DLtP2 & $0.0 \pm 0.0$ & $46.7 \pm 2.5$ & $0.4 \pm 0.3$ & $0.8 \pm 0.2^{\dagger \neq \#}$ & $1.2 \pm 0.2^{\#}$ & $56.1 \pm 2.3^{\ddagger}$ \\
\hline DLtP3 & $0.0 \pm 0.0$ & $45.2 \pm 1.9^{\star \#}$ & $1.3 \pm 0.3^{\star \dagger \ddagger \varsigma}$ & $0.7 \pm 0.3^{\dagger ま \#}$ & $0.8 \pm 0.2^{* \dagger}$ & $50.4 \pm 1.4^{\dagger \S}$ \\
\hline LL ARtP1 & $6.0 \pm 4.2$ & $46.5 \pm 2.5$ & $1.1 \pm 0.4$ & $2.5 \pm 0.3$ & $2.6 \pm 0.3$ & $43.9 \pm 3.0$ \\
\hline ARtP2 & $4.0 \pm 2.8$ & $52.1 \pm 2.9$ & $1.4 \pm 0.4$ & $2.2 \pm 0.3$ & $2.6 \pm 0.3$ & $49.5 \pm 2.8^{\star}$ \\
\hline ALtP1 & $2.3 \pm 2.3$ & $42.4 \pm 2.0^{*}$ & $0.5 \pm 0.3^{\dagger}$ & $0.6 \pm 0.3^{* \dagger}$ & $0.9 \pm 0.2^{\dagger}$ & $40.6 \pm 1.8^{\dagger}$ \\
\hline ALtP2 & $2.7 \pm 2.7$ & $42.8 \pm 2.0^{\star}$ & $0.7 \pm 0.4$ & $0.6 \pm 0.2^{*^{\dagger}}$ & $1.2 \pm 0.2^{\dagger}$ & $42.0 \pm 1.7^{\dagger}$ \\
\hline PRtP1 & $6.6 \pm 4.4$ & $47.2 \pm 2.0$ & $1.7 \pm 0.4$ & $1.6 \pm 0.2$ & $3.3 \pm 0.3$ & $41.7 \pm 1.9$ \\
\hline PRtP2 & $5.0 \pm 3.5$ & $50.9 \pm 3.0$ & $1.7 \pm 0.4$ & $1.9 \pm 0.4$ & $3.2 \pm 0.3$ & $42.4 \pm 2.0$ \\
\hline PLtP1 & $6.8 \pm 5.5$ & $47.9 \pm 2.2$ & $1.6 \pm 0.3$ & $0.5 \pm 0.2^{* \dagger}$ & $1.1 \pm 0.3^{* \dagger}$ & $38.9 \pm 1.8$ \\
\hline PLtP2 & $5.4 \pm 3.6$ & $53.0 \pm 2.5$ & $1.5 \pm 0.3$ & $0.8 \pm 0.4^{* \dagger}$ & $1.1 \pm 0.3^{* \dagger}$ & $41.0 \pm 1.9$ \\
\hline
\end{tabular}




\section{Continued}

\begin{tabular}{|c|c|c|c|c|c|c|}
\hline Foot SoRtP1 & $12.6 \pm 5.3$ & $56.9 \pm 2.0$ & $0.3 \pm 0.3$ & $2.8 \pm 0.4$ & $0.1 \pm 0.1$ & $55.8 \pm 2.9$ \\
\hline SoRtP2 & $6.4 \pm 4.4$ & $64.7 \pm 3.0^{*}$ & $0.3 \pm 0.3$ & $2.9 \pm 0.5$ & $0.2 \pm 0.1$ & $59.9 \pm 1.6$ \\
\hline SoRtP3 & $0.0 \pm 0.0^{*}$ & $53.2 \pm 1.9^{\dagger}$ & $0.3 \pm 0.3$ & $2.0 \pm 0.3$ & $0.1 \pm 0.1$ & $52.3 \pm 2.7^{\dagger}$ \\
\hline SoRtP4 & $8.6 \pm 4.2^{\ddagger}$ & $55.1 \pm 1.5^{\dagger}$ & $0.3 \pm 0.3$ & $2.4 \pm 0.4$ & $0.4 \pm 0.1$ & $60.4 \pm 1.9^{\ddagger}$ \\
\hline SoLtP1 & $16.7 \pm 10.4$ & $61.5 \pm 2.8^{\ddagger}$ & $0.3 \pm 0.3$ & $3.0 \pm 0.4$ & $0.2 \pm 0.1$ & $54.8 \pm 2.0^{\dagger \#}$ \\
\hline SoLtP2 & $16.4 \pm 10.0$ & $61.1 \pm 2.1^{\text {耕 }}$ & $0.3 \pm 0.3$ & $2.0 \pm 0.3$ & $0.1 \pm 0.1$ & $54.4 \pm 2.6^{\dagger}$ \\
\hline SoLtP3 & $0.0 \pm 0.0^{\star \#}$ & $56.1 \pm 1.9^{\dagger}$ & $0.3 \pm 0.3$ & $3.1 \pm 0.5^{\varsigma}$ & $0.3 \pm 0.2$ & $53.1 \pm 2.2^{\#}$ \\
\hline SoLtP4 & $8.4 \pm 6.8$ & $56.5 \pm 1.9^{\dagger}$ & $0.3 \pm 0.3$ & $2.3 \pm 0.4$ & $0.1 \pm 0.1$ & $54.5 \pm 2.4$ \\
\hline DRtP1 & $5.6 \pm 5.6$ & $56.4 \pm 1.9$ & $0.3 \pm 0.3$ & $2.1 \pm 0.2$ & $0.2 \pm 0.1$ & $48.7 \pm 1.1$ \\
\hline DRtP2 & $0.6 \pm 0.6$ & $55.0 \pm 1.5$ & $0.3 \pm 0.3$ & $2.6 \pm 0.3$ & $0.5 \pm 0.2$ & $47.6 \pm 1.2$ \\
\hline DRtP3 & $0.5 \pm 0.2$ & $56.5 \pm 1.9$ & $0.3 \pm 0.3$ & $3.0 \pm 0.3^{*}$ & $0.5 \pm 0.2$ & $52.3 \pm 1.7^{\dagger}$ \\
\hline DLtP1 & $3.5 \pm 3.5$ & $56.1 \pm 1.4$ & $0.3 \pm 0.3$ & $2.2 \pm 0.2$ & $0.6 \pm 0.1^{\star}$ & $48.8 \pm 1.4$ \\
\hline DLtP2 & $0.1 \pm 0.1$ & $54.6 \pm 2.0$ & $0.3 \pm 0.3$ & $2.0 \pm 0.2^{\ddagger}$ & $0.2 \pm 0.1^{\#}$ & $48.7 \pm 1.8$ \\
\hline DLtP3 & $0.1 \pm 0.1$ & $53.8 \pm 1.9$ & $0.3 \pm 0.3$ & $1.7 \pm 0.1^{\ddagger}$ & $1.0 \pm 0.2^{\star \#}$ & $54.8 \pm 1.8^{\text {*\#\#S }}$ \\
\hline
\end{tabular}

All data were presented as the mean \pm SE. P1-P5, point of face; A, anterior; P, posterior; Rt and Lt, right and left side; UL, upper limb; Pa, palm; D, dorsal part; So, sole; LL, lower limb. Statistically significant differences exist in face P1 vs. P2, P3, P4, and P5 ( $\left.{ }^{*} p<0.05\right)$, in P2 vs. P3, P4, and P5 ( $\left.{ }^{\dagger} p<0.05\right)$, in P3 vs. $\mathrm{P} 4$ and $\mathrm{P} 5\left({ }^{\ddagger} p<0.05\right)$, in P4 vs. P5 ( $\left.{ }^{*} p<0.05\right)$, respectively. Statistically significant differences exist in ear ARtP1 vs. ALtP1 $\left({ }^{*} p<0.05\right)$, PRtP1 vs. PRtP2, PLtP1, and PLtP2 ( $\left.{ }^{*} \mathrm{p}<0.05\right)$, PRtP2 vs. PLtP1, and PLtP2 $\left({ }^{\dagger} p<0.05\right)$, in PLtP1 vs. PLtP2 $\left({ }^{\ddagger} p<0.05\right)$, respectively. Statistically significant differences exist in neck AP1 vs. PP1 $\left({ }^{*} p<0.05\right)$. Statistically significant differences exist in upper limb ARtP1 vs. ARtP2, ALtP1, and ALtP2 $\left({ }^{*} p<0.05\right)$, in ARtP2 vs. ALtP1, and ALtP2 $\left({ }^{\dagger} p<0.05\right)$, in ALtP1 vs. ALtP2 $\left({ }^{\ddagger} p<0.05\right)$, in PRtP1 vs. PRtP2, PLtP1, and PLtP2 $\left({ }^{*} p<0.05\right)$, in PRtP2 vs. PLtP1, and PLtP2 $\left({ }^{\dagger} p<0.05\right)$, in PLtP1 vs. PLtP2 $\left({ }^{\ddagger} p<0.05\right)$, respectively. Furthermore, statistically significant differences exist in hand PaRtP1 vs. PaRtP2, PaRtP3, PaRt4, PaLtP1, PaLtP2, PaLtP3, and PaLtP4 ( $\left.{ }^{*} p<0.05\right)$, in PaRtP2 vs. PaRtP3, PaRtP4, PaLtP1, PaLtP2, PaLtP3, and PaLtP4 $\left({ }^{\dagger} p<0.05\right)$, in PaRtP3 vs. PaRtP4, PaLtP1, PaLtP2, PaLtP3, and PaLtP4 $\left({ }^{\ddagger} p<0.05\right)$, in PaRtP4 vs. PaLtP1, PaLtP2, PaLtP3, and PaLtP4 $\left({ }^{\sharp} p<0.05\right)$, in PaLtP1 vs. PaLtP2, PaLtP3, and PaLtP4 $\left({ }^{\S} p<0.05\right)$, in PaLtP2 vs. PaLtP3, and PaLtP4 $\left({ }^{s} p<0.05\right)$, in PaLtP3 and PaLtP4 $\left({ }^{8} p<0.05\right)$, in DRtP1 vs. DRtP2, DRtP3, DLtP1, DLtP2, and DLtP3 $\left({ }^{*} p<0.05\right)$, in DRtP2 vs. DRtP3, DLtP1, DLtP2, and DLtP3 $\left({ }^{\dagger} p<0.05\right)$, in DRtP3 vs. DLtP1, DLtP2, and DLtP3 $\left({ }^{\ddagger} p<0.05\right)$ in DLtP1 vs. DLtP2, and DLtP3 $\left({ }^{*} p<0.05\right)$, in DLtP2 vs. DLtP3 $\left({ }^{\$} p\right.$ $<0.05)$. Statistically significant differences exist in lower limb ARtP1 vs. ARtP2, ALtP1, and ALtP2 ( $\left.{ }^{*} p<0.05\right)$, in ARtP2 vs. ALtP1, and ALtP2 $\left({ }^{\dagger} p<0.05\right)$, in ALtP1 vs. ALtP2 ( $\left.{ }^{\ddagger} p<0.05\right)$, in PRtP1 vs. PRtP2, PLtP1, and PLtP2 $\left({ }^{*} p<0.05\right)$, in PRtP2 vs. PLtP1, and PLtP2 $\left({ }^{\dagger} p<0.05\right)$, in PLtP1 vs. PLtP2 $\left.{ }^{\ddagger} p<0.05\right)$. Statistically significant differences exist in foot SoRtP1 vs. SoRtP2, SoRtP3, SoRt4, SoLtP1, SoLtP2, SoLtP3, and SoLtP4 ( $\left.{ }^{*} p<0.05\right)$, in SoRtP2 vs. SoRtP3, SoRtP4, SoLtP1, SoLtP2, SoLtP3, and SoLtP4 $\left({ }^{\dagger} p<0.05\right)$, in SoRtP3 vs. SoRtP4, SoLtP1, SoLtP2, SoLtP3, and SoLtP4 $\left({ }^{\ddagger} p<0.05\right)$, in SoRtP4 vs. SoLtP1, SoLtP2, SoLtP3, and SoLtP4 ( $\left.{ }^{*} p<0.05\right)$, in SoLtP1 vs. SoLtP2, SoLtP3, and SoLtP4 $\left({ }^{\$} p<0.05\right)$, in SoLtP2 vs. SoLtP3, and SoLtP4 $\left({ }^{\$} p<0.05\right)$, in SoLtP3 and SoLtP4 $\left({ }^{\star} p<0.05\right)$, in DRtP1 vs. DRtP2, DRtP3, DLtP1, DLtP2, and DLtP3 $\left({ }^{*} p<0.05\right)$, in DRtP2 vs. DRtP3, DLtP1, DLtP2, and DLtP3 $\left({ }^{\dagger} p<0.05\right)$, in DRtP3 vs. DLtP1, DLtP2, and DLtP3 $\left({ }^{\ddagger} p<0.05\right)$ in DLtP1 vs. DLtP2, and DLtP3 $\left({ }^{*} p<0.05\right)$, in DLtP2 vs. DLtP3 $\left({ }^{\S} p<0.05\right)$, respectively. 